\title{
NEUROLAW AND THE NEUROSCIENCE OF FREE WILL: AN OVERVIEW
}

\section{NEURODERECHO Y LA NEUROCIENCIA DEL LIBRE ALBEDRÍO: UNA VISIÓN GENERAL}

\begin{abstract}
Renato César Cardoso $a^{*}$
\end{abstract}
Fechas de recepción y aceptación: 18 de marzo de 2021 y 20 de octubre de 2021

DOI: https://doi.org/10.46583/scio_2021.21.843

Abstract: Due to the advent of modern neuroscience, several scientific disciplines have developed entirely new theories, perspectives, and methodologies. The substantial advances and discoveries made in this field over the last decades, especially those concerned with human cognition and behavior, have steered the course of many traditional research areas and given rise to others, like neuroethics and neurolaw. Here we take a look at some of the general characteristics of the growing field of neurolaw, an interdisciplinary field that dwells on the intersection of law and neuroscience. We then discuss the neuroscience of free will, one of the most impacting and pressing topics in the neurolaw debate, with special attention to Libet's paradigm, recent scientific developments, and novel interpretations that question customary assumptions about it.

Keywords: Neurolaw, neuroethics, free will, neuroscience, law, Libet's paradigm.

\footnotetext{
${ }^{a}$ Departamento de Filosofía del Derecho. Facultad de Derecho. Universidad Federal de Minas Gerais (UFMG), Brasil.

${ }^{*}$ Correspondencia: Universidad Federal de Minas Gerais. Faculdad de Derecho. Avenida João Pinheiro, 100, Centro. 30130-180 Belo Horizonte. MG. Brasil.

E-mail: renatoccardoso@ufmg.br
} 
Resumen: Debido al advenimiento de la neurociencia moderna, várias disciplinas científicas han desarrollado teorías, perspectivas y metodologías completamente nuevas. Los sustanciales avances y descubrimientos realizados en este campo durante las últimas décadas, especialmente los relacionados con la cognición y el comportamiento humanos, han marcado el rumbo de muchas áreas de investigación tradicionales y han dado lugar a otras, como la neuroética y el neuroderecho. Aquí echamos un vistazo a algunas de las características generales del creciente campo del neuroderecho, un campo interdisciplinario que se concentra en la intersección del derecho y la neurociencia. Luego discutimos la neurociencia del libre albedrío, uno de los temas más impactantes y urgentes en el debate del neuroderecho, con especial atención al paradigma de Libet, los desarrollos científicos recientes y las interpretaciones novedosas que cuestionan los supuestos habituales al respecto.

Palabras clave: neuroderecho, neuroética, libre albedrío, neurociencia, derecho, paradigma de Libet.

\section{$\S 1$. Neurolaw}

\subsection{Introduction}

Due to the advent of modern neuroscience, several traditional scientific disciplines have developed entirely new theories, perspectives, and methodologies. The substantial advances and discoveries made in this field over the last three decades have steered the course of many research areas, especially those concerned with human cognition and behavior. To name only a few, we have witnessed the emergence of neuroeconomics (Camerer, Loewenstein \& Prelec, 2005), neuropolitics (Schreiber, 2017), neurophilosophy (Churchland, 1989; Muñoz, 2013), neuromarketing (Lee, Broderick \& Chamberlain, 2007) and, of course, neuroethics (Illes, Sahakian, 2013; Clausen \& Levy, 2015) and neurolaw (Shen, 2010; García-López, Mercurio, Nijdam-Jones, Morales \& Rosenfeld, 2019).

Nevertheless, the adoption of neuroscientific knowledge in different sciences has also met considerable challenges, resistance, and even hard skepticism 
(Lilienfeld, Aslinger, Marshall, \& Satel, 2017) ${ }^{1}$. Neurolaw is no exception to the rule and influential voices have argued that traditional legal categories are sufficient and able to deal with the change neuroscience has brought so far (Moore, 2020; Morse, 2004). However, the ever-growing interest in the field we witness today - and the many different areas of research in neurolaw that have developed recently - suggest otherwise. ${ }^{2}$ This article consists of a brief overview of some of the most important themes, works and discussions in neurolaw and the neuroscience of free will.

\subsection{Neurolaw \& neuroethics}

Neurolaw (also referred to as law and neuroscience) is an emerging interdisciplinary area that dwells on the intersection of law and neuroscience (Belcher \& Sinnott-Armstrong, 2010). Traditionally, neurolaw has been described as the study of neuroscientific evidence as used in the courtroom (Catley, 2016). However, since the word was coined (Taylor, Harp \& Elliott, 1991), its meaning has become more encompassing and complex, covering different new fields, and stretching across disciplines such as philosophy, criminology, psychology, public policy and cognitive/social neuroscience, among others.

There is considerable overlap between neurolaw and the very proximate field of neuroethics (Clausen \& Levy, 2015) and some have even considered

\footnotetext{
${ }^{1}$ For example: "The future of neuroscience is exceedingly bright. Yet because neurohype is ubiquitous in popular culture, it may impel many laypersons, policy makers, and scientists outside of neuroscience, including psychologists, to reflexively dismiss many of the legitimate advances and promises of neuroscience. Hence, curbing the rhetorical excesses of neurohype is essential to safeguarding the scientific integrity of neuroscience. Neurohype can also render many people, including educated laypersons, vulnerable to the seductive charms of "brainscams". Heightened vigilance toward neurohype is especially crucial in light of the increasing incursion of neuroimaging data into the courtroom" (Lilienfeld, Aslinger, Marshall, \& Satel, 2017: 241).

${ }^{2}$ See Muñoz, García-López \& Rusconi (2020) for a recent example of many different ways in which law and neuroscience intersect. It is relevant to note that this brief section 1 is meant as an introductory set of initial ideas and references, designed to give the reader an introductory notion of some of the important work in the field of neurolaw. There are several significant publications that could not be included here due to space issues. A more comprehensive bibliography can be found at the Law and Neuroscience Bibliography on www.lawneuro.org/bibliography.php (last visited July, 2021).
} 
the first to be a branch of the second (Meynen, 2014). As a matter of fact, it has been proposed that both disciplines even share the same structure. One of the most influential definitions of neuroethics describes it as being twofold, comprising both the ethics of neuroscience and the neuroscience of ethics:

The intimate connection between our brains and our behaviors, as well as the peculiar relationship between our brains and ourselves, generate distinctive questions that beg for the interplay between ethical and neuroscientific thinking. The motivation for the newfound interest in bringing together neuroscientists, ethicists, journalists, philosophers, policy makers arises from the intuition that our ever-increasing understanding of the brain mechanisms underlying diverse behaviors has unique and potentially dramatic implications for our perspective on ethics and for social justice. These are the issues that warrant the introduction of a new area of intellectual and social discourse. As I see it, there are two main divisions of neuroethics: the ethics of neuroscience and the neuroscience of ethics. Each of these can be pursued independently to a large extent, but perhaps most intriguing is to contemplate how progress in each will affect the other (Roskies, 2002:21).

Neurolaw, conversely, could be loosely divided the same way: the law of neuroscience and the neuroscience of law:

The structure proposed here builds on these ideas, translating the bipartite structure that Roskies proposed early on for the developing field of neuroethics, namely the "ethics of neuroscience" and the "neuroscience of ethics" into the "law of neuroscience" and the "neuroscience of law." This remains an appealing organizational structure, and is reflected in the organization of major recent anthologies in the field. One of the reasons it is appealing is that it brings together two domains of inquiry that might otherwise remain separate, and invites one to look for feedback links or possible interactions between the two (Chandler, 2018: 592).

Arguably, there is room for a third category here in the case of neurolaw: neuroscience in the law. This category would deal exclusively with questions about how neuroscience should be used in the courts as evidence, carefully weighting its scientific and legal admissibility, the possibilities for overclaims and the potential benefits, which could be sizable: 
Of course, the relevance of neuroscience to law depends intimately on the specific legal issue and context. And neuroscientific evidence is but one kind of evidence, to be weighed alongside other kinds. But, speaking quite generally, neuroscientific evidence might aid law in at least seven (sometimes overlapping) ways:

1. Buttressing - by increasing juror confidence in a conclusion to which other, non-neuroscientific evidence already independently points (such as in the context of "diminished capacity" determinations);

2. Challenging - by calling into question or contradicting either other evidence in a case or a relevant legal assumption (such as those reflected in certain evidentiary rules);

3. Detecting - by identifying the existence of legally relevant facts (such as injuries, lies, or pain);

4. Sorting - by separating people into useful categories (such as those most likely to respond to drug rehabilitation);

5. Intervening - by providing new methods to achieve legal goals (such as through pharmacological interventions that would help to reduce recidivism);

6. Explaining - by illuminating decision pathways with information that may lead to more informed and less biased decisions (such as in the context of third-party punishment [TPP] decisions);

7. Predicting - by improving law's ability to estimate probabilities of future behavior (such as future violence) (Jones, Marois, Farah \& Greely, 2013: 17624).

Obviously, each one of these topics deserves a deeper look and careful analysis. That can't be accomplished within the limits of this article but one should point out that there are possible pitfalls in all of them, both moral and legal. For instance, there is a lot to be said and problematized about the usage, benefits, limits and problems of neurointerventions (Vincent, Nadelhoffer \& McCay, 2020). Prediction can also be challenging in several ways, not the least in the potential threats it can materialize to fundamental rights such as non-discrimination or the presumption of innocence. New paradigms, like that 
of "neuroprevention" (Ruiz, Muñoz, 2021), may have an important role to play in the future, by reconciling advances in neuroscientific knowledge about different behavioral outcomes and inalienable fundamental rights and guarantees.

Additionally, it is easy to note that most of the criticism raised originally against neuroethics translates strongly to neurolaw and should be addressed, although not in the same way, but taking that into consideration. Those include reductionism, essentialism, neurohype or neuromania, naturalistic fallacy or abdicating to science the role of making legal policy, lack of independence, dilettantism and over-breadth (Chandler, 2018). Even though these are important objections, that have to be taken seriously, so far none of them has managed to present an insurmountable case against neurolaw and progresses in neuroscience continues to push it forward.

Such progress, however, has to be accompanied by caution. Even though the field is itself relatively new, there is much to be said and acknowledged in the history of the interactions between law and neuroscience. These interactions date back at least to the XIX century ${ }^{3}$ and were not always without problems. Even the briefest overview will not be able to exclude names such as Cesare Lombroso (1896), Francis Galton (1891), or Egas Moniz (1937), advocates of phrenology, eugenics, and frontal lobotomy. More than an indictment on neurolaw, these examples serve as a cautionary tale. Recognizing this past shows us that we can significantly profit, as a society, from an improved understanding of human behavior through neuroscience; it also shows the need to be humble about our findings and prudent about their possible applications (Shen, 2016). ${ }^{4}$

\footnotetext{
${ }^{3}$ For a deeper study into the history of this relation between neuroscience and moral responsibility, see: Verplaetse, J. (2009). Localizing the moral sense: Neuroscience and the search for the cerebral seat of morality, 1800-1930.

${ }^{4}$ In his article, Shen discusses four often overlooked moments in the history of law and brain sciences: "These moments are (1) foundational medico-legal dialogue in the nineteenth and early twentieth centuries, (2) the introduction of electroencephalography evidence into the legal system in the mid-twentieth century, (3) the use of psychosurgery for violence prevention in the 1960s and 1970s, and, most recently, (4) the development of neurolaw in personal injury litigation in the late 1980s and 1990s." (Shen, 2016). He acknowledges that a comprehensive list should be much longer: "An extended treatment could consider many more topics, including situating neurolaw within the much longer history of medicine and law; nineteenth-century investigations into the moral sciences; the development of toxicology in the nineteenth century; early neuroscience research to find the seat of consciousness; brain death; connections with the literature on the ethical, legal, and social implications of genetics; history
} 


\subsection{Important topics in neurolaw}

Undoubtedly though, there is growing interest in neurolaw. The number of publications in the field has grown exponentially in the last decade (Shen, 2010) and several conferences and events were held; many jurists (academics, judges, lawyers, prosecutors) have taken an interest and even participated in training sessions on neuroscience. There are many reasons for this. One of them is a growing awareness of the remarkable technological developments in the neurosciences in recent decades. New methods and tools for brain imaging such as positron emission tomography (PET) and functional magnetic resonance imaging (fMRI), as well as data analytics and artificial intelligence have been combined and delivered numerous important results that expand our comprehension of the human brain and behavior. Striking discoveries unveil the possibility of looking at enduring legal questions under a new light and broader perspective (Jones, Schall \& Shen, 2014).

These new neuro-technological capabilities bring hope that at least some of these questions can find better answers than the ones we have found so far. For example, questions pertaining to legal responsibility, culpability, insanity, free will, autonomy, decision-making and other related themes can be better illuminated by this new scientific knowledge. Arguably the most important debate in contemporary philosophy of law is that of the relationship between morality and legality; it too has been entirely reshaped by recent knowledge and insights made possible by the developments in neuroscience, notably with functional neuroimaging (Yang, Shao, Zhang, Li, Li, Li \& Lee 2019; Decety \& Wheatley, 2015; Fumagalli \& Priori, 2012; Schleim, Spranger, Erk \& Walter 2011).

These same developments in neuroimaging (most particularly fMRI) have sparked some of the more traditional debates in the field, including lie detection, memory, and testimony, juvenile justice, elderly justice, pain assessment (Amirian, 2013). These are good examples of topics that show up commonly in the law and neuroscience debates. The limits, possibilities, and legal

of expert witnesses; FDA and drug development; administration of antipsychotic drugs; and the use of "facilitated communication" with autistic individuals" (Shen, 2016: 668).

SCIO. Revista de Filosofía, n. ${ }^{\circ}$ 21, Noviembre de 2021, 55-81, ISSN: 1887-9853 
admissibility of such technologies is an ongoing debate (Wagner, Bonnie, Casey, Davis, Faigman, Hoffman, ... \& Yaffe, 2016; Poldrack, 2018). Besides neuroimaging, more direct interventions such as brain stimulation using transcranial direct current stimulation (tDCS) or transcranial magnetic stimulation (TMS), neuro-enhancements and nootropics (Bard et al., 2018) have also raised a lot of interest and concern.

Nonetheless, one should notice that all this advance in the field is far from uncontentious and there is ample room for overclaims and unwarranted hype, which advises for caution going forward (Fernandez-Duque, Evans, Christian, Hodges, 2015; Morse, 2011). Apart from the denounced hype, there are important claims that there might be some deeper conceptual and philosophical problems the field should be worried about (notably the mereological fallacy - attributing psychological traits to the brain itself, not to the person as a whole, which would be the correct stance), not only in neurolaw (Pardo \& Patterson, 2015) but in some foundational issues in neuroscience as well (Bennett \& Hacker, 2003). Unsurprisingly, both claims faced strong refutations and authoritative rebuttals (Bennett, Dennett, Hacker \& Searle, 2007; Levy, 2014).

\subsection{Neurolaw revolution?}

Some have argued that neuroscience has not changed anything substantial in the current landscape of law and that it may not change it substantially in the future:

The new neuroscience poses familiar moral, social, political, and legal challenges that can be addressed using equally familiar conceptual and theoretical tools. Discoveries that increase our understanding and control of human behavior may raise the stakes, but they do not change the game. Future discoveries may so radically alter the way we think about ourselves as persons and about the nature of human existence that massive shifts in moral, social, political, and legal concepts, practices, and institutions may ensue. For now, however, neuroscience poses no threat to ordinary notions 
of personhood and responsibility that undergird our morals, politics, and law (Morse, 2004: 90). ${ }^{5}$

Others have envisioned a much deeper shift in the way we comprehend legal institutions. Joshua Greene and Jonathan Cohen have argued, in a very influential paper entitled "For the law, neuroscience changes nothing and everything", that the effects of the neurolaw revolution will come by the way of changing how people understand human behavior in a very deep sense:

Neuroscience is unlikely to tell us anything that will challenge the law's stated assumptions. However, we maintain that advances in neuroscience are likely to change the way people think about human action and criminal responsibility by vividly illustrating lessons that some people appreciated long ago. Free will as we ordinarily understand it is an illusion generated by our cognitive architecture. Retributivist notions of criminal responsibility ultimately depend on this illusion, and, if we are lucky, they will give way to consequentialist ones, thus radically transforming our approach to criminal justice. At this time, the law deals firmly but mercifully with individuals whose behaviour is obviously the product of forces that are ultimately beyond their control. Some day, the law may treat all convicted criminals this way. That is, humanely (Cohen \& Greene, 2004: 1784). ${ }^{6}$

\footnotetext{
${ }^{5}$ There is an important point to be made here: even if the common legal practice does not get affected by neuroscientific discoveries in the future, there is still much to be learned from it. This is a relevant argument as far as philosophy of law is concerned: "For example, better understanding of the neural basis of capacities underlying criminal responsibility might shed new light on the standards that we apply for individuals having or lacking criminal responsibility. In addition, neuroscientific studies might illuminate the neural mechanisms that underlie those features of people in virtue of which they are criminally responsible for their behavior. And so they would help us to understand criminal responsibility better, without thereby supporting an argument for or against holding any person or class of people criminally responsible. While knowing more about a problem can be a first step to solving it, knowing more might be valuable simply because it involves knowing more. In the same way that the knowledge that the neuroscience of memory provides is of value even before we make use of it to treat memory disorders, or to improve our memories, if neuroscience can help us to understand the neural nature of criminally responsible behavior, that would be of value, even if we cannot use such knowledge to reduce crime or increase justice. Such results would add to human knowledge not just of the brain but of one of the most socially important phenomena to which the brain gives rise: crimes for which people are responsible and deserving of punishment." (Maoz \& Yaffe, 2016: 123-124).

${ }^{6}$ Some scholars go even further: "I suggest that all, or virtually all, of our law largely depends on a gross misunderstanding of its subject - the human agent. The law often fails because the legal doctrine
} 
A third view, like the one supported by Kolber in his paper "Will There Be a Neurolaw Revolution?" (2014), predicts something in between: although traditional legal theories, institutions, and jurisprudence will not be fundamentally altered, new neuroscientific methods will surely have an important impact on law and its practice. The great development of brain imaging in the last decades has improved our capacity to measure distress and to infer people's thoughts, for example. Thought privacy will become more of an issue and we will probably have less of it in the future; progress in artificial intelligence will steadily change our understanding of how the law is formed, interpreted, and applied (Kolber, 2014).

A good overview of the current trends and forthcoming paths of the neurolaw field was put together by Francis Shen, with an interesting list of possibilities for the future. These include addressing mind-body dualism in legal doctrine and practice, virtual reality and the law, the regulation of mobile consumer neurotechnology, concussions in youth and professional sports, legal implications of early-onset dementia detection, revisiting brain-based memory recognition, brain biomarkers and brain-based prediction, revisiting brain death and disorders of consciousness, privacy and brain hacking, admissibility of novel neuroscientific evidence, artificial intelligence and its use in neuroscience, cognitive enhancement through direct brain intervention, governance of induced pluripotent stem cell human chimeras, non-human animal brains and non-human animal rights, and, last but not least, global neurolaw (Shen, 2016).

This last topic is especially important if we consider that the biggest part of neurolaw research to this day has been concentrated in the United States and Europe, and that sometimes it is transplanted to other countries and cultures without the necessary care or critical evaluation. It seems crucial to develop research projects and networks that depict the different realities in places like Africa, Asia, and Latin America with an eye to cultural aspects that may be

misunderstands what it means to be human. Further, extant comprehensive interpretive theories of law, theories that combine the positive and the normative, provide the arguments in support of the doctrine's misapprehension. It is the noninstrumental theories that make the fundamental conceptual error. Instrumental theories fail too, but their failure is largely attributable to empirical rather than conceptual error. Instrumental theory could take account of an authentic understanding of human agency; noninstrumental theory denies the materialism and the determinism that define human agency and so could not understand what it means to be human" (Alces, 2018: XIII). 
of influence to the neurolaw debate (García-López, Mercurio, Nijdam-Jones, Morales \& Rosenfeld, 2019).

One very significant fact that must be acknowledged is that the first declaration of "neurorights" is being discussed by the Parliament in Chile and might soon be part of its constitutional law. The project proposes to implement five new "human rights":

1. The right to mental privacy;

2. The right to identity and personal autonomy;

3. The right to free will and self-determination

4. The right to equal access to cognitive enhancement

5. The right to protection against algorithmic bias or automatized decision-making discrimination. ${ }^{7}$

To be sure, there is still a lot to be clarified as to how terms like "mental", "identity", "free will" or "enhancement" should or would be interpreted and about the extension that these new "neurorights" will be implemented, but undoubtedly this is a very important, foundational step in the history of neurolaw. Further discussion on this is deeply needed, and it shall include scientists, legislators, jurists, philosophers, psychologists, and especially the civil society directly affected by these deep legal changes.

Not only practical implications are troublesome though; several questions on philosophy and theory of law arise from this new scenario. The current progress in neuroscientific research has been exponential and along with it came several domains in which law is bound to enter the discussion, either by being called upon to regulate conducts and the application of new technologies or by being challenged in some of its core assumptions on how human behavior is constituted (Picozza, 2016). It is in this latter issue that we find our next topic of inquiry: the neuroscience of free will.

${ }^{7} \mathrm{http}: / /$ www.senado.cl/appsenado/templates/tramitacion/index.php?boletin_ini=13828-19 (last accessed in July, 2021). 


\section{§2. THE NEUROSCIENCE OF FREE WILL}

For the better part of its trajectory, neurolaw has dealt prominently with questions relating to legal responsibility, especially on criminal law. Several cases involving brain damage (from trauma, tumors etc.) and the ensuing consequences for behavior and culpability have generated vivid discussions amid lawyers, philosophers, and neuroscientists alike. Challenging long time established ideas about conscious will, free will and moral responsibility, neuroscience has raised an entire set of new problems for legal reasoning, shaking the grounds of traditional practical philosophy.

The question of the existence of free will has been one of the most enduring and discussed problems in the history of philosophy. Even though there are still considerable arguments about the origins of the idea of free will (Frede, 2011), few would deny the centrality of it in western philosophy. It was also the object of heated controversy in physics, biology, and psychology over the last two centuries. The basic discussions not only dwell on the question of the existence of free will itself, but also on the relations that exist (or that should exist) between free will and moral responsibility (Fischer, Kane, Pereboom, \& Vargas, 2009; Muñoz, 2012). The ensuing questions about the logic, legitimacy, or utility of punishment, obviously related, did not fail to promote debate as well. The problem of what the justice system would look like - if it would look like anything at all - in the absence of the notion of free will is one of the most intriguing in the philosophy of law today. Free will skepticism, once a marginal position in the field, is rapidly growing and demanding significant attention from respected academics (Focquaert, Caruso, Shaw \& Pereboom, 2020). Hard incompatibilism, a philosophical position advanced by Pereboom (2003), deserves special attention in this category: it states that either the universe is utterly deterministic or quantically indeterministic (random), but that neither position can possibly be compatible with the idea of free will. Compatibilists and libertarians find themselves hard pressed to circumvent Pereboom's argument.

But before diving into the muddy waters of these philosophical discussions on moral and legal responsibility, one should take a deeper look at the novel arguments neuroscience has brought to the metaphorical table and analyze how 
well they stand against criticism and how much of an impact they may have on our traditional concept of free will and on the legal doctrines that depend on it. ${ }^{8}$

The empirical approach to the problem recently taken by neuroscience-oriented researchers has produced a swerve in the old debate which cannot be ignored by modern-day philosophers, jurists, psychologists, and alike. These developments took off in 1964 when Kornhuber and Decker published significant findings on EEG research: by averaging the measures of hundreds of finger movements of voluntary subjects they discovered a specific negative event-related potential that preceded voluntary action. They called it "bereitschaftpotential", which later was translated to "readiness potential" (RP) (Kornhuber \& Decker, 1964).

This inspired the interest of many neuroscientists and several experiments followed. ${ }^{9}$ One neurophysiologist, in particular, built on this to develop a new experimental paradigm that would produce one of the most debated and contested finding in neuroscience to this day: Benjamin Libet. His seminal findings (Libet, Gleason, Wright \& Pearl, 1983) reshaped the neuroscience of free will discussion forever forward (Frith \& Haggard, 2018). ${ }^{10}$ What was so revolutionary about it? By combining the measurement of the readiness potential with the self-reported timing of onset of the subject's conscious intentions he was able to probe the temporal relation established between a voluntary motor action (M), conscious will (W), and the brain wave activity involved in it (RP).

The design was clever: subjects were asked to flex their wrists at the time of their own choosing, all the while looking at a revolving fast-paced spot on a clock. They were also instructed to report to the experimenter the location of that spot when they first became aware of their intention to flex their wrists.

${ }^{8}$ In this regard, see: Hirstein, W., Sifferd, K. L., \& Fagan, T. K. (2018). Responsible Brains: Neuroscience, Law, and Human Culpability. MIT Press.

${ }^{9}$ The most extreme of these experiments is probably the recent successful attempt to measure the readiness potential preceding a 192-meter bungee jumping dive: Nann, M., Cohen, L. G., Deecke, L., \& Soekadar, S. R. (2019). To jump or not to jump-The Bereitschaftspotential required to jump into 192-meter abyss. Scientific reports, 9(1), 1-9.

${ }^{10}$ Of course, it also reshaped the philosophical and ethical debate. See, for example: Sinnott-Armstrong, W., \& Nadel, L. (Eds.). (2010). Conscious will and responsibility: A tribute to Benjamin Libet. Oxford University Press. 
The results were contrary to what common phenomenology leads us to expect. They seemed to show that, instead of conscious intention being the driving force in the process of motor action initiation, it was merely a subproduct or even an epiphenomenon of much earlier and unconscious brain activity. In fact, the experiment showed that while conscious intention (W) preceded voluntary action by about $200 \mathrm{~ms}$, the readiness potential (RP) preceded it by a considerably longer interval, of about $550 \mathrm{~ms}$. (Libet, 1985)

These findings have been replicated numerous times in various labs and settings, sometimes with somewhat different settings and results (Haggard \& Eimer, 1999; Brass, Lynn, Demanet \& Rigoni, 2013). Different techniques and methodologies have also been used and successfully found equivalent or sometimes even more powerful results. Notably in 2008 (Soon, Brass, Heinze \& Haynes) using functional magnetic resonance imaging (fMRI) and multivariate analysis techniques, we were able to decode the outcome of the subject's behavior in the experimental task up to ten seconds before the behavior itself:

There has been a long controversy as to whether subjectively 'free' decisions are determined by brain activity ahead of time. We found that the outcome of a decision can be encoded in brain activity of prefrontal and parietal cortex up to $10 \mathrm{~s}$ before it enters awareness. This delay presumably reflects the operation of a network of high-level control areas that begin to prepare an upcoming decision long before it enters awareness (Soon, Brass, Heinze \& Haynes, 2008:1).

These impressively large results received a lot of attention in the neuroscience of free will, even though it is still not clear if the results reflect predictive brain pre-activation or if they decoded some kind of decision bias. It is important to notice that the results showed only a discrete percentage above chance, of $6 \%$ to $10 \%$ (Soon, Brass, Heinze \& Haynes, 2008).

Another extremely significant study that produced robust results in favor of the notion that the RP precedes conscious intention was conducted in 2011 (Fried, Mukamel \& Kreiman). By using intracranial recordings, they were able to circumvent several limitations intrinsic to the kind of information provided using the EEG (like the need for several trials in order to average out the results). They also had better location discrimination as well as the possibility 
to determine a single neuron's firing rate. The end result was an accuracy of about $70 \%$ up to $500 \mathrm{~ms}$ before W. ${ }^{11}$

Studies such as those discussed above strengthen the case for free will skepticism. On the other hand, multiple voices have argued for different interpretations to be adopted about those findings. Libet himself did not agree with the common interpretation endorsed by many. He defended that although the traditional ideas about free will we are actually severely affected by his discoveries still there was room for some kind of free will, at least in the shape of what he called the "veto" power:

For spontaneous voluntary acts, RP onset preceded the uncorrected Ws by about $350 \mathrm{~ms}$ and the Ws corrected for $\mathrm{S}$ by about $400 \mathrm{~ms}$. The direction of this difference was consistent and significant throughout, regardless of which of several measures of RP onset or W were used. It was concluded that cerebral initiation of a spontaneous voluntary act begins unconsciously. However, it was found that the final decision to act could still be consciously

${ }^{11}$ This is a more detailed description of the experiment and its results: "In a seminal study, Fried et al. (2011) carried out the Libet experiment in a group of patients with intracranial recordings. The electrodes were placed in different parts of the medial frontal cortex, including the SMA/preSMA and the anterior cingulate cortex (ACC). Such intracranial recordings have a few advantages over classical EEG recordings. First, it is possible to determine the exact location from which the activity is originating. Second, the signal is reliable enough to carry out single trial analyses. Third, one can investigate the firing rate of single neurons as well as the number of neurons that are recruited at a specific point in time. Fried et al. (2011) replicated Libet's basic result, showing that activity in units in the medial frontal cortex increased firing a few hundred milliseconds before W. Interestingly, they also demonstrated that the number of units that were recruited increased before $\mathrm{W}$. In addition to this conceptual replication of Libet's findings, they reported some unique results. A variety of response patterns was observed for different neurons. Some neurons continuously increased the firing rate prior to W, very similar to what is observed in the RP in EEG recordings. However, some neurons also showed a sharp increase of the neural firing prior to $\mathrm{W}$, indicating that the RP might reflect an integration of different activation patterns. Most important, recording of multiple units and the high reliability of the recordings also allowed the use of multivariate pattern analysis (MVPA) to decode the onset of neural activity indexed as a departure from baseline. In contrast to the classical RP approach, which is based on trial averages, this is an approach based on single trial activation. By looking at the pattern of activity across different units it was possible to decode departure from baseline activity with an accuracy of $70 \%$ as early as $500 \mathrm{~ms}$ before W. By pooling units across participants, the prediction accuracy could even be increased. To summarize, Fried et al. (2011) not only replicated Libet's results using intracranial recordings, they also provided a quantification of how well neural activity can predict the subjective awareness of intention prior to W." Brass, M., Furstenberg, A., \& Mele, A. R. (2019: 10-11). 
controlled during the $150 \mathrm{~ms}$ or so remaining after the specific conscious intention appears. Subjects can in fact "veto" motor performance during a 100-200-ms period before a prearranged time to act. The role of conscious will would be not to initiate a specific voluntary act but rather to select and control volitional outcome. It is proposed that conscious will can function in a permissive fashion, either to permit or to prevent the motor implementation of the intention to act that arises unconsciously (Libet, 1985: 529).

Both Libet's interpretation and the more conventional conclusions about his experiments, namely that free will is proved a false concept (or at least dubious one, in need of significant resignification), met considerable opposition. Several fronts were subject to attacks and challenges: questions about the ecological validity and the unnatural setting of the experiment, about the reliability of the measurement of the subjective time of intention (Dominik, Dostál, Zielina, Šmahaj, Sedláčková, \& Procházka, 2017), about what the RP really means and what it is correlated with, about when the intention is formed, and many others (Roskies, 2011; Brass, Furstenberg \& Mele, 2019).

One of these challenges, in particular, deserves a closer look. In a much-discussed article, "An accumulator model for spontaneous neural activity prior to self-initiated movement" Schurger, Sitt and Dehaene (2012) made a very solid argument that we need a different explanation of the premovement buildup of neuronal activity (RP):

According to our model, when the imperative to produce a movement is weak, the precise moment at which the decision threshold is crossed leading to movement is largely determined by spontaneous subthreshold fluctuations in neuronal activity. Time locking to movement onset ensures that these fluctuations appear in the average as a gradual exponential-looking increase in neuronal activity. Our model accounts for the behavioral and electroencephalography data recorded from human subjects performing the task and also makes a specific prediction that we confirmed in a second electroencephalography experiment: Fast responses to temporally unpredictable interruptions should be preceded by a slow negative-going voltage deflection beginning well before the interruption itself, even when the subject was not preparing to move at that particular moment (Schurger, Sitt \& Dehaene, 2012: 2904). 
Influential philosophers and neuroscientists have raised different objections and proposed different interpretations following this conclusion that the RP may reflect the stochastic impact of normal fluctuations in neuronal activity. Brass, Furstenberg and Mele (2019), for example, in an article entitled "Why neuroscience does not disprove free will", proposed a new model to interpret the findings on the paradigm so far. The conditional intention and integration to bound (COINTOB) model manages to integrate accumulated evidence on Libet's paradigm in a coherent and highly explanatory way.

First a conditional intention is formed that reflects participants' understanding of the task instruction. This conditional intention configures the integration to bound (ITB) process that leads to the choice. The bias reflects an initial preference for one response alternative. The ITB process is furthermore determined by the accumulation rate and the bound. In the example above, evidence first accumulates towards the non chosen response option. The choice is made when the accumulation process crosses the bound. This is also around the moment when participants become aware of their choice (W). The time between the beginning of the trial and $\mathrm{W}$ is the waiting time. The time between $\mathrm{W}$ and the response is the implementation time. A veto process can be implemented after participants become aware of their intention and before the point of no return. Such a veto process might be driven by a change-of-mind bound that is crossed based on post-decisional evidence accumulation (Brass, Furstenberg \& Mele, 2019: 40).

Based upon other models of decision-making, particularly those of perceptual decision-making, they propose the occurrence of information accumulation from internal origin (not external, like perception), and stochastic neural activity. Evidence for each option is accumulated up to the crossing of a threshold that triggers the decision:

In such a model, the RP is a neural index of the continuous integration of information and stochastic neural activity. Importantly, the integration process is not the consequence of a decision but the basis for the decision. The decision is only made when the threshold is crossed. This means that the RP and the LRP do not reflect a ballistic process that necessarily leads to action but rather a gathering of evidence. While the crossing of the decision threshold can in principle occur outside the awareness of participants, 
the Libet task requires participants to indicate when they become aware of their intention. In such a context, $\mathrm{W}$ might indicate the crossing of the decision threshold. Importantly, the decision process is configured by conscious conditional intentions that participants form at the beginning of the experiment as a result of the task instructions. These conditional intentions determine which factors influence the decision process (Brass, Furstenberg \& Mele, 2019: 38).

Also, important, the model makes room for the veto shown in other experiments, in a short interval after the threshold is crossed, probably based on evidence accumulated after the decision and that crosses the lower bound, causing a change of mind.

There is still much work to be done on this problem and certainly the COINTOB model is not the last word we will hear, but it shows perfectly well how much we have advanced since the first Libet's experiments. It also makes a very strong point in showing that common beliefs about what the experiment means are, at minimum, very problematic. It seems plausible to say that, at least today, Libet-style experiments in fact do not disprove free will without a reasonable doubt. The broader claim that names the article, on the other hand - "Why neuroscience does not disprove free will" - may prove to be a little hasty. After all, there is more to the neuroscience of free will than just Benjamin Libet. ${ }^{12}$

More than providing a single experiment that will definitely put the idea of free will to rest, it seems that neuroscience might do the trick of undermining the common notion of free will by tackling down one of its closer correlates: dualism. Undoubtedly dualism is at the center stage as one of the most rebutted theories by modern-day science, not only by neuroscience but also by basic science as well (Ryle, 2009; Dennett, 1993; Crick \& Clark, 1994; Bunge, 2014).

In his now-classic work on consciousness, Dennett explains the problem with dualism:

\footnotetext{
${ }^{12}$ See, for example: "Cognitive, social, and neuropsychological studies of apparent mental causation suggest that experiences of conscious will frequently depart from actual causal processes and so might not reflect direct perceptions of conscious thought causing action.” Wegner, D. M. (2003). Also: Blackmore, S., Clark, T. W., Hallett, M., Haynes, J. D., Honderich, T., Levy, N., ... \& Waller, B. (2013).
} 
...the return signals, the directives from mind to brain (...) are not physical; they are not light waves or sound waves or cosmic rays or streams of subatomic particles. No physical energy or mass is associated with them. How, then, do they get to make a difference to what happens in the brain cells they must affect, if the mind is to have any influence over the body? A fundamental principle of physics is that any change in the trajectory of any physical entity is an acceleration requiring the expenditure of energy, and where is this energy [in mind-brain interaction] to come from? It is this principle of the conservation of energy that accounts for the physical impossibility of "perpetual motion machines", and the same principle is apparently violated by dualism. This confrontation between quite standard physics and dualism has been endlessly discussed since Descartes's own day, and is widely regarded as the inescapable and fatal flaw of dualism (Dennett, 1993: 35).

Much has been discussed in the philosophical arenas about the relationship we should (or should not) establish between free will and dualism. It is not our intention to delve into this complex - and undeniably important - debate right now. For our purposes here, it will suffice to say that it has been shown empirically that free will beliefs are strongly related to dualism beliefs (Forstmann \& Burgmer 2018; Wisniewski, Deutschländer \& Haynes, 2019).

This brings us to another important debate that should be at least mentioned, even though they cannot be properly pursued here: going a step further, leaving behind the discussion about the existence of free will, we have to acknowledge another area that has developed very interesting research in the last years and that matters deeply to the neurolaw debate: the question of free will beliefs and their impact on decision making. Many scales to measure free will beliefs (and related beliefs like determinism or dualism) have been formulated, but the two most commonly used are the FAD-Plus (Paulhus, Carey, 2011) and the Free Will Inventory (Nadelhoffer, Shepard, Nahmias, Sripada, \& Ross, 2014). ${ }^{13}$

\footnotetext{
${ }^{13}$ While both have been used in several experiments and both have pros and cons that can't be properly addressed here, we favor the Free Will Inventory because it seems more appropriate to probe some of the nuances in the free will/responsibility debate that is so central to neuroethics and neurolaw. Also, the fact that it has been validated to the Portuguese (Vilanova, Costa, Nadelhoffer, \& Koller, 2018) encourages the development of cross-cultural research that can include and compare data from the Brazilian and
} 
Several studies have shown that there are interesting relations between free will beliefs and different kinds of behavior and recent neuroscientific studies have investigated the mechanisms that underlie this phenomenon (Rigoni, Kühn, Sartori \& Brass, 2011). Free will beliefs have been shown to influence how we evaluate other's behaviors (Genschow, Rigoni, \& Brass, 2017) and some studies even focus specifically on judges and legal decision-making (Genschow, Hawickhorst, Rigoni, Aschermann \& Brass, 2020; Shariff, Greene, Karremans, Luguri, Clark, Schooler, ... \& Vohs, 2014). This is a very promising research field that will generate a lot of discussion in the future. After all, if neuroscience is set to change anything in the law and in the legal system itself, it will have to do it by changing peoples underlying beliefs about justice, responsibility, retributivism and so forth. One of our most pressing tasks right now is trying to understand how.

\section{$\S 3$. Conclusion}

There is a rapidly growing literature both in neurolaw and in the neuroscience of free will. Obviously, both fields intersect with each other deeply. Foundational questions in the theory and philosophy of law have been reshaped by modern neuroscientific knowledge, and research in behavior/cognitive neuroscience is constantly faced with ethical and legal conundrums, both about their practical applications and the questions it raises for the nature of normative thinking itself. Although interdisciplinarity is often more defended than actually practiced, jurists and neuroscientists alike would greatly benefit from working closer together and learning from each other's expertise. After all, both of them share an extended interest in a common object: human behavior. Their perspectives and final goals might be very far apart from each other, but crossing the disciplinary borders offers great promises, not only for law and neuroscience but for the humanities and the natural sciences in general.

Portuguese populations. As a matter of fact, the impact of linguistic and cultural influences on free will beliefs is also a field in which there is still lot to be done. 
Neuroethics, neurolaw, and the neuroscience of free will are emerging and burgeoning areas, that will continue to develop jointly, in parallel with the advances in the cognitive/behavioral sciences. This brief effort to bring together and present some of the main themes, works and challenges in these fields is meant to show how much more is still to be done and conclude, in traditional fashion, that further research is deeply needed on these topics. Sometimes clichés can also be true.

\section{REFERENCES}

Alces, P. The Moral Conflict of Law and Neuroscience. (2018). Chicago, IL: Chicago University Press.

Amirian, J. (2013). Weighing the admissibility of fMRI technology under FRE 403: For the law, fMRI changes everything-and nothing. Fordham Urb. LJ, 41, 715.

Bard, I., Gaskell, G., Allansdottir, A., da Cunha, R. V., Eduard, P., Hampel, J., ... \& Zwart, H. (2018). Bottom up ethics-neuroenhancement in education and employment. Neuroethics, 11(3), 309-322.

Belcher, A., \& Sinnott-Armstrong, W. (2010). Neurolaw. Wiley Interdisciplinary Reviews: Cognitive Science, 1(1), 18-22.

Bennett, M. R. \& Hacker, P. M. S. (2003). Philosophical foundations of neuroscience (Vol. 79). Oxford, UK: Blackwell.

Bennett, M. R., Dennett, D., Hacker, P., \& Searle, J. (2007). Neuroscience and philosophy: Brain, mind, and language. New York, NY: Columbia University Press.

Blackmore, S., Clark, T. W., Hallett, M., Haynes, J. D., Honderich, T., Levy, N., ... \& Waller, B. (2013). Exploring the illusion of free will and moral responsibility. Lanham, MD: Lexington Books

Brass, M., Furstenberg, A., \& Mele, A. R. (2019). Why neuroscience does not disprove free will. Neuroscience \& Biobehavioral Reviews, 102, 251-263. 
Brass, M., Lynn, M. T., Demanet, J., \& Rigoni, D. (2013). Imaging volition: what the brain can tell us about the will. Experimental brain research, 229(3), 301-312.

Bunge, M. (2014). The mind-body problem: A psychobiological approach. Elmsford, NY: Pergamon Press Inc.

Camerer, C., Loewenstein, G., \& Prelec, D. (2005). Neuroeconomics: How neuroscience can inform economics. Journal of Economic Literature, 43(1), 9-64.

Catley, P. (2016). The Future of Neurolaw. European Journal of Current Legal Issues, 22(2).

Chandler, J. A. (2018). Neurolaw and neuroethics. Cambridge Quarterly of Healthcare Ethics, 27(4), 590-598.

Churchland, P. S. (1989). Neurophilosophy: Toward a unified science of the mind-brain. Cambridge, MA: MIT Press.

Clausen, J., \& Levy, N. (Eds.). (2015). Handbook of neuroethics. Heidelberg: Springer Netherlands.

Crick, F., \& Clark, J. (1994). The astonishing hypothesis. Journal of Consciousness Studies, 1(1), 10-16.

Darby, R. R., Joutsa, J., Burke, M. J., \& Fox, M. D. (2018). Lesion network localization of free will. Proceedings of the National Academy of Sciences, 115(42), 10792-10797.

Decety, J., \& Wheatley, T. (Eds.). (2015). The moral brain: A multidisciplinary perspective. Cambridge, MA: MIT Press.

Dennett, D. C. (1993). Consciousness explained. London: Penguin UK.

Dominik, T., Dostál, D., Zielina, M., Šmahaj, J., Sedláčková, Z., \& Procházka, R. (2017). Libet's experiment: Questioning the validity of measuring the urge to move. Consciousness and cognition, 49, 255-263.

Fernandez-Duque, D., Evans, J., Christian, C., Hodges, S. Superfluous Neuroscience Information Makes Explanations of Psychological Phenomena More Appealing. Journal of Cognitive Neuroscience (2015) 27:5, 926-944

Fischer, J. M., Kane, R., Pereboom, D., \& Vargas, M. (2009). Four views on free will. Malden, MA: Blackwell Publishing. 
Focquaert, F., Caruso, G., Shaw, E., \& Pereboom, D. (2020). Justice without retribution: interdisciplinary perspectives, stakeholder views and practical implications. Neuroethics, 13(1), 1-3.

Forstmann, M., \& Burgmer, P. (2018). A free will needs a free mind: Belief in substance dualism and reductive physicalism differentially predict belief in free will and determinism. Consciousness and cognition, 63, 280-293.

Frede, M. (2011). A free will: Origins of the notion in ancient thought. Los Angeles, CA: University of California Press.

Fried, I., Mukamel, R., \& Kreiman, G. (2011). Internally generated preactivation of single neurons in human medial frontal cortex predicts volition. Neuron, 69(3), 548-562.

Frith, C. D., \& Haggard, P. (2018). Volition and the brain-revisiting a classic experimental study. Trends in neurosciences, 41(7), 405-407.

Fumagalli, M., \& Priori, A. (2012). Functional and clinical neuroanatomy of morality. Brain, 135(7), 2006-2021.

Galton, F. (1891). Hereditary genius. New York, NY: D. Appleton.

García-López, E., Mercurio, E., Nijdam-Jones, A., Morales, L. A., \& Rosenfeld, B. (2019). Neurolaw in Latin America: Current status and challenges. International Journal of Forensic Mental Health, 18(3), 260-280.

Genschow, O., Hawickhorst, H., Rigoni, D., Aschermann, E., \& Brass, M. (2020). Professional Judges' Disbelief in Free Will Does Not Decrease Punishment. Social Psychological and Personality Science, 1948550620915055 ;

Genschow, O., Rigoni, D., \& Brass, M. (2017). Belief in free will affects causal attributions when judging others' behavior. Proceedings of the National Academy of Sciences of the United States of America, 114(38), 1007110076. doi:10.1073/pnas.1701916114

Greene, J., \& Cohen, J. D. (2004). For the Law, Neuroscience Changes Nothing and Everything. Philosophical Transactions of the Royal Society of London Series B-Biological Sciences.

Haggard, P., \& Eimer, M. (1999). On the relation between brain potentials and the awareness of voluntary movements. Experimental brain research, 126(1), 128-133. 
Hirstein, W., Sifferd, K. L., \& Fagan, T. K. (2018). Responsible Brains: Neuroscience, Law, and Human Culpability. Cambridge, MA: MIT Press.

Illes, J., \& Sahakian, B. J. (Eds.). (2013). Oxford handbook of neuroethics. Oxford: Oxford University Press.

Jones, O. D., Marois, R., Farah, M. J., \& Greely, H. T. (2013). Law and neuroscience. Journal of Neuroscience, 33(45), 17624-17630.

Jones, O. D., Schall, J. D., \& Shen, F. X. (2015). Law and neuroscience. New York, NY: Wolters Kluwer Law \& Business.

Kolber, A. Will There Be a Neurolaw Revolution? Indiana Law Journal, Vol. 89, p. 807, 2014

Kornhuber, H. H., \& Deecke, L. (1964, January). Hirnpotentialanderungen beim Menschen vor und nach Willkurbewegungen dargestellt mit Magnetbandspeicherung und Ruckwartsanalyse. In Pflugers Archiv-European Journal of Physiology (Vol. 281, No. 1, p. 52).

Lee, N., Broderick, A. J., \& Chamberlain, L. (2007). What is 'neuromarketing'? A discussion and agenda for future research. International journal of psychophysiology, 63(2), 199-204.

Levy, N. (2014). Is neurolaw conceptually confused? The journal of ethics, 18(2), 171-185.

Libet, B. (1985). Unconscious cerebral initiative and the role of conscious will in voluntary action. Behavioral and brain sciences, 8(4), 529-539.

Libet, B., Gleason, C. A., Wright, E. W., \& Pearl, D. K. (1993). Time of conscious intention to act in relation to onset of cerebral activity (readiness-potential). Neurophysiology of consciousness (pp. 249-268). Boston, MA: Birkhäuser

Lilienfeld, S. O., Aslinger, E., Marshall, J., \& Satel, S. (2018). Neurohype: A field guide to exaggerated brain-based claims. In L. S. M. Johnson \& K. S. Rommelfanger (Eds.), Routledge handbooks in applied ethics. The Routledge handbook of neuroethics (p. 241-261). Routledge/Taylor \& Francis Group.

Lombroso, C. (1880). L'uomo delinquente (Vol. 85). Torino: Fratelli Bocca. 
Maoz, U., \& Yaffe, G. (2016). What does recent neuroscience tell us about criminal responsibility?. Journal of Law and the Biosciences, 3(1), 120-139.

Meynen, G. (2014). Neurolaw: neuroscience, ethics, and law. Ethical Theory and Moral Practice, 17(4), 819-829.

Moniz, E. (1937). Prefrontal leucotomy in the treatment of mental disorders. American Journal of Psychiatry, 93(6), 1379-1385.

Moore, M. S. (2020). Mechanical Choices: The Responsibility of the Human Machine. New York, NY: Oxford University Press.

Morse, S. (2004, January). New neuroscience, old problems: legal implications of brain science. In Cerebrum: the Dana forum on brain science (Vol. 6, No. 4, pp. 81-90).

Morse, S. (2011). Avoiding irrational neurolaw exuberance: a plea for neuromodesty. Law, Innovation and Technology, 3(2), 209-228.

Muñoz, J.M. (2012). Hacia una sistematización de la relación entre determinismo y libertad. Daimon Revista Internacional de Filosofia, (56), 5-19.

Muñoz, J.M. (2013). Neurofilosofía y libre albedrío. Daimon: Revista Internacional de Filosofía 59: 57-70.

Muñoz, J. M., García-López, E., \& Rusconi, E. (2020). Neurolaw: The Call for Adjusting Theory Based on Scientific Results. Frontiers in Psychology, 11, 2479.

Nadelhoffer, T., Shepard, J., Nahmias, E., Sripada, C., \& Ross, L. T. (2014). The free will inventory: Measuring beliefs about agency and responsibility. Consciousness and cognition, 25, 27-41.

Nann, M., Cohen, L. G., Deecke, L., \& Soekadar, S. R. (2019). To jump or not to jump-The Bereitschaftspotential required to jump into 192-meter abyss. Scientific reports, 9(1), 1-9.

Paulhus, D. L., \& Carey, J. M. (2011). The FAD-Plus: Measuring lay beliefs regarding free will and related constructs. Journal of personality assessment, 93(1), 96-104.

Pardo, M. S., \& Patterson, D. (2015). Minds, brains, and law: The conceptual foundations of law and neuroscience. New York, NY: Oxford University Press. 
Pereboom, D. (2003) Living without free will. New York, NY: Cambridge University Press

Picozza, N. (2016) Neurolaw: An introduction. New York, NY: Springer

Poldrack, R. A. (2018). The new mind readers: What neuroimaging can and cannot reveal about our thoughts. Princeton, NJ: Princeton University Press.

Rigoni, D., Kühn, S., Sartori, G., \& Brass, M. (2011). Inducing disbelief in free will alters brain correlates of preconscious motor preparation: The brain minds whether we believe in free will or not. Psychological science, 22(5), 613-618.

Roskies, A. (2002). Neuroethics for the new millenium. Neuron, 35(1), 21-23.

Roskies, A. L. (2011). Why Libet's studies don't pose a threat to free will. Conscious will and responsibility, 11-22.

Ryle, G. (2009). The concept of mind. London, UK: Hutchinson \& Co

Ruiz, A., Muñoz, J. (2021). Neuroprevention: Developing Legal Policies in Risk Assessment Without Aspiring to Predict Crime. Journal of Science and Law, 9(1): 1-5. doi:10.35005/y991-wv96. https://jscilaw.org/index. php?view $=$ article \&id $=14$

Schleim, S., Spranger, T. M., Erk, S., \& Walter, H. (2011). From moral to legal judgment: the influence of normative context in lawyers and other academics. Social cognitive and affective neuroscience, 6(1), 48-57.

Schreiber, D. (2017). Neuropolitics: Twenty years later. Politics and the Life Sciences, 36(2), 114-131.

Schurger, A., Sitt, J. D., \& Dehaene, S. (2012). An accumulator model for spontaneous neural activity prior to self-initiated movement. Proceedings of the National Academy of Sciences, 109(42), E2904-E2913.

Shariff, A. F., Greene, J. D., Karremans, J. C., Luguri, J. B., Clark, C. J., Schooler, J. W., ... \& Vohs, K. D. (2014). Free will and punishment: A mechanistic view of human nature reduces retribution. Psychological science, 25(8), 1563-1570.

Shen, F. X. (2010). The law and neuroscience bibliography: Navigating the emerging field of neurolaw. International Journal of Legal Information, 38(3), 352-399. 
Shen, F. X. (2016). Law and neuroscience 2.0. Ariz. St. LJ, 48, 1043.

Shen, F. X. (2016). The overlooked history of neurolaw. Fordham L. Rev., $85,667$.

Sinnott-Armstrong, W., \& Nadel, L. (Eds.). (2010). Conscious will and responsibility: A tribute to Benjamin Libet. Oxford, UK: Oxford University Press.

Soon, C. S., Brass, M., Heinze, H. J., \& Haynes, J. D. (2008). Unconscious determinants of free decisions in the human brain. Nature neuroscience, 11(5), 543-545.

Taylor, J. S; J. Anderson Harp; Tyron Elliott (1991). Neuropsychologists and Neurolawyers. Neuropsychology. 5 (4): 293-305

Verplaetse, J. (2009). Localizing the moral sense: Neuroscience and the search for the cerebral seat of morality, 1800-1930. Dordrecht: Springer.

Vilanova, T. R. S. F., Costa, Â. B., Nadelhoffer, D. G. T. T., \& Koller, S. H. (2018). Validity evidence of the free will inventory for the brazilian population. Avaliação Psicológica, 17(1), 1-11.

Vincent, N. A., Nadelhoffer, T., \& McCay, A. (Eds.). (2020). Neurointerventions and the Law: Regulating Human Mental Capacity. New York, NY: Oxford University Press.

Wagner, A. D., Bonnie, R. J., Casey, B. J., Davis, A., Faigman, D. L., Hoffman, M. B., ... \& Yaffe, G. (2016). fMRI and lie detection. Vanderbilt Law Research Paper No. 17-10

Wegner, D. M. (2003). The mind's best trick: how we experience conscious will. Trends in cognitive sciences, 7(2), 65-69.

Wisniewski, D., Deutschländer, R., \& Haynes, J. D. (2019). Free will beliefs are better predicted by dualism than determinism beliefs across different cultures. PloS one, 14(9), e0221617.

Yang, Q., Shao, R., Zhang, Q., Li, C., Li, Y., Li, H., \& Lee, T. (2019). When morality opposes the law: an fMRI investigation into punishment judgments for crimes with good intentions. Neuropsychologia, 127, 195-203. 